\title{
Content Analysis of Post-Disaster Socio-Psychological Research Focusing on Methodology and Subject Research \\ Saeedeh Asadi ${ }^{1} \mathbb{D}$, Ali Sharghi ${ }^{2}$
}

Date of submission: 10 Jun. 2019, Date of acceptance: 12 Aug. 2019

\section{Original Article}

Abstract

INTRODUCTION: The impact of disasters on the mental and physical health of affected communities requires planning for socio-psychological recovery, recognizing various dimensions, and research on the arising issues. The present study is conducted with the aim to focus on methodological and subject research approaches in international post-disaster studies in the framework of research design, target society, and measurement of key structures, in order to identify existing research gaps in this field.

METHODS: In the present study, a purposeful post-disaster content analysis was performed quantitatively and qualitatively on socio-psychological studies in 39 journals indexed in databases. After the purposeful and specific steps, 73 studies were coded in an accurate review process, and then the codes extracted (research strategies, research project implementation, highlighted topics, sampling method, statistical population, and data collection tools) were analyzed in Excel software and presented in the form of descriptive statistics.

FINDINGS: Cross-sectional studies with quantitative strategy, random sampling method, standardized structured questionnaire, and large statistical population have the highest frequency. The predominant subjects studied on an individual scale were the individual postdisaster psychological consequences and on a collective scale were indicators associated with socio-psychological recovery.

CONCLUSION: The imbalance in the socio-psychological studies of disasters and the recovery indicators in both individual and collective scales require paying attention to the subjects related to the individual recovery and mental health and a deeper understanding of the sociopsychological consequences of disasters. In addition to the current research approaches, the investigations on the post-traumatic neuroscience will be growing in the future perspective. Expanding the scope of quantitative research and neuroscience requires standardized measurement scales in developing countries. The reliability of the study findings was $71.5 \%$.

Keywords: Content Analysis; Socio-Psychological Studies; Disasters; Methodology, Subject Research

How to cite this article: Asadi S, Sharghi A. Content Analysis of Post-Disaster SocioPsychological Research Focusing on Methodology and Subject Research. Sci J Rescue Relief 2019; 11(3): 201-13.

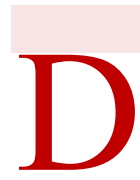
Introduction

isasters are natural or man-made environmental phenomena that can cause deaths, stress, physical harm, and economic destruction, and are very important to deal with (1). Goldman and Galea defined three characteristics for disasters: first, threat, injury, or death of a large number of human, second, the impact on social processes and the destruction of collective resources, and third, secondary consequences such as mental and physical health consequences among survivors (2). Evidence is indicative of the lasting effects of disasters. In this regard, with the approval of the Sendai Framework for Disaster Risk Reduction 2015-2030, health became one of the key elements in reducing the risk of disasters.

1- PhD Candidate, Architecture, School of Architecture and Urban Planning, Shahid Rajaee Teacher Training University, Tehran, Iran

2- PhD, School of Architecture and Urban Planning, Shahid Rajaee Teacher Training University, Tehran, Iran

Correspondence to: Saeedeh Asadi, Email: saeedehasadi1363@gmail.com 
Paragraph 330 of this framework emphasizes the "mental health, improving rehabilitation programs for psychological support and health services for all those in need" (3). Given the literature, planning for long-term recovery will have a potential effect on reducing some of the permanent effects of the disaster (4). It is also important to pay attention to equality in the mental health of the injured community (5). While the mental health and psychosocial recovery of affected communities are one of the main goals of post-disaster reorganization and rehabilitation programs, in the event of a disaster, less attention is paid to them and the interventions are focused on them non-purposefully and unintentionally. Among the reasons, in the first place, is the limitation of the issues raised in this field to the area of opinion, and the lack of mastery and application of correct and efficient research methods in the post-incident fields.

In this regard, the design of post-disaster housing can be mentioned as one of the important potentials in creating long-term resilience for communities located in vulnerable areas (6). Despite the centrality of housing in rehabilitation processes in disaster literature (7), experts express growing concern about the effectiveness of post-traumatic housing on the socio-psychological resilience of local communities (8-10). "Houses are failed before people have a chance to live in and post-incident settlements lead to serious physical and psychological problems for their residents" Aquilino declared (11). Despite the spread of disaster-related literature, the focus seems to have failed to address coping as a cognitivebehavioral process with the potential to affect well-being, social functioning, and public health (12). These issues indicate the poor research in the field of disasters. Therefore, due to the unknown nature, complexity, and in some cases the uncertainties in the field of disasters, investigations are led to the exploratory nature and uncertainty in various aspects and connect with the fields of sociology, behavior, and human psychology (13). Thus, it is necessary to know the various sociopsychological consequences of the disaster scientifically and methodically, and to investigate the issues raised in such societies in order to intervene correctly, efficiently, and accurately.

Any relief, intervention, or recovery in the various socio-psychological dimensions of the disaster requires research and analysis of the characteristics of the context of the disaster $(14,15)$.
In addition, the consequences of the disaster are affected by social contexts such as local history, resource management strategies, and interactions among residents. Therefore, they need appropriate approaches in cognition and rehabilitation $(16,17)$. Lack of accurate knowledge of these issues will lead to obstacles in rehabilitating and reorganizing the conditions of affected communities, and thus following persistent psychological effects such as post-traumatic stress disorder (PTSD), anxiety, and depression (18) or various social consequences. Therefore, it is necessary for researchers to be aware of the need for an effective research plan in the study on health issues and the disaster socio-psychological consequences, in order to create a deep insight into the issues, solutions, and strategies ahead in this field.

The aim of this study is to identify some of the practical and executive solutions of methodology and effective research in socio-psychological studies of disaster-affected communities, to identify practical approaches to research, and the future horizon of knowledge in research and challenges in this field. Therefore, the present study will try the answer the following questions:

1. What are the research methodological strategies in post-disaster socio-psychological studies?

2. What are the challenges of using common post-disaster research approaches to sociopsychological issues?

3. What techniques and tools can be implemented the above-mentioned research methods with?

4. What is the horizon of knowledge ahead in post-disaster socio-psychological research?

5. What are the most important issues in postdisaster socio-psychological studies?

\section{Theoretical foundations}

Post-disaster research: Disaster research faces many specific practical and ethical challenges, which is even more prominent in research on human societies because the need to explain the phenomenon in the context of a disaster requires norms that do not exist under normal circumstances (19). Experts have differing views on the methodology of disaster research. Drabek states that the methodological problems faced by individuals in disaster studies are similar to those faced in other social phenomena (20). In contrast, Mileti believes that disaster research is drastically different from public sociological research (21). Stallings also acknowledges that in the case of disasters, the research method is no different from 
normal social conditions and the distinguishing feature is the application of conventional methods (22). In other words, in post-disaster research, the context of the research, rather than the method of implementation, makes them different. According to experts, the field of research is one of the factors influencing research in the event of a disaster. One of the important areas of research in such situations is the study of problems related to socio-psychological issues, and research in this area is more complex due to stress caused by traumatic events and a range of psychologicalemotional and physiological consequences (23). These conditions may be prominent for years after traumatic disasters, and it is vital for researchers to be aware of them in the field of disasters (24).

\section{Development of a post-disaster socio- psychological research framework}

Natural disasters have ambiguous effects on the lives of the people affected, as physically, mentally, and emotionally. It is not surprising, then, that researchers interpret the disaster as a kind of traumatic event (25). Material damages related to the psychological part of the disaster include physical and mental health and spiritual damages such as maturation, social relations, health, and the ability to endure suffering (26). Researchers have been studying the long-term health effects of natural disasters for years. Such investigations face numerous methodological challenges. Therefore, the design and implementation of epidemiological studies in a disaster-affected society requires considering various research factors.

UNDP [Bureau for Crisis Prevention and Recovery (BCPR)] cites the lack of clarity on the best way to measure and evaluate the impact of disasters (27). Fritz et al. also declare that "analysis of social and psychological indicators that determine human behavior during and after a disaster cause methodological problems in this area" (28). From Galea et al.'s point of view, post-traumatic psychological studies face significant legal and methodological challenges due to the unexpected nature of the disaster, the displacement of communities, and disruption of services. They consider the methodological challenges of post-disaster psychosocial studies in four key areas of determination of target population, obtaining an appropriate sample of the affected people in society, implementing the research plan, and measuring key structures (29). Kulka and Schlenger also focused on four issues: 1. identifying the target population and selecting the sample, 2. identifying the relevant groups for comparison and control, 3 . identifying appropriate case studies, and 4. collecting comprehensive information (30). Amaratunga et al. in Sri Lanka Reconstruction also considered the important research methodological issues as determination of research plan, strategies, and techniques (31). Therefore, the framework of the present study is summarized in Figure 1 based on the analysis of the above-mentioned views.

\section{Methods}

The basis of the present study was content analysis with two quantitative and qualitative approaches. Holsti considers content analysis to be a method of systematic and objective inference from the specific features of a message (32). Moreover, Sandelowski defines content analysis as one of the methods of analyzing studies in order to summarize, describe, and interpret data (33). Among the studies in this field, one can refer to the systematic content analysis carried out by Roudini et al. (34). This study considered the effects of predisaster preparedness on mental health and then analyzed them from a methodological perspective. In contrast, in the present study, the studies were analyzed in the post-disaster period in the field of socio-psychological problems and interventions from the perspective of the subject and method of research and in association with the stated goals.
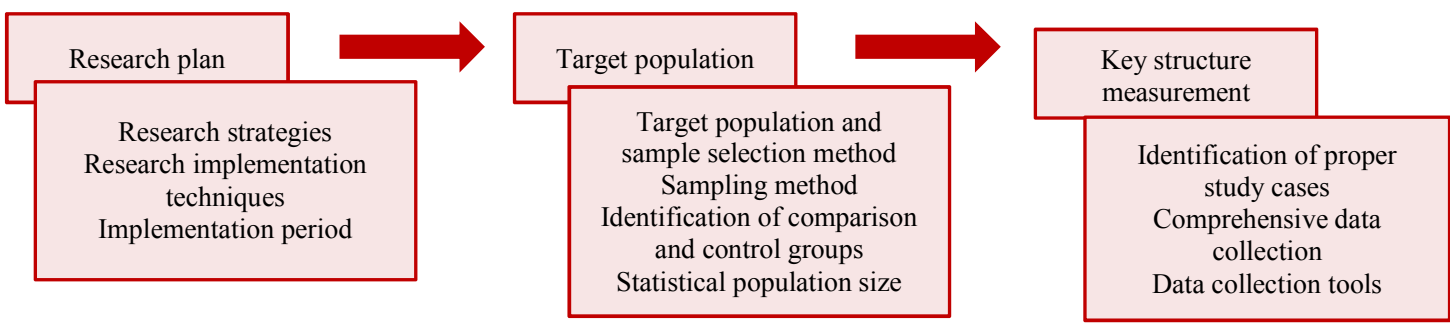

Figure 1. Study framework 
The study was performed in two stages and specific and systematic sampling, data collection, and analysis methods were used (35). The beginning of the study process was a review of the existing and related literature in the approximate period of the last 20 years, between the years 2000 and 2020 using the study keywords (Figure 2).

\begin{tabular}{|c|}
\hline \multicolumn{2}{c|}{ Keywords } \\
Pisaster Disorder Mental health Psychosocial consequences \\
Trauma Research method
\end{tabular}

Figure 2. Study keywords

In the first stage, the cluster sampling method was performed randomly, because the use of random sampling rules in content analysis ensures the validity of the conclusions and increases the generalizability $(36,37)$, so the studies were indexed systematically by searching in the valid global databases. The purposeful surveys were then performed on the sources in the first-hand documents. The process of conducting the study and studies extracted from the databases is described in Figure 3 and Table 1.

From the selected studies until 2020, there have been 8 disaster-related articles in Iran that were conducted between 2008 (about the Bam earthquake) and 2019 (the Kermanshah and East Azerbaijan earthquakes).

Table 1. Characteristics of post-disaster socio-psychological studies

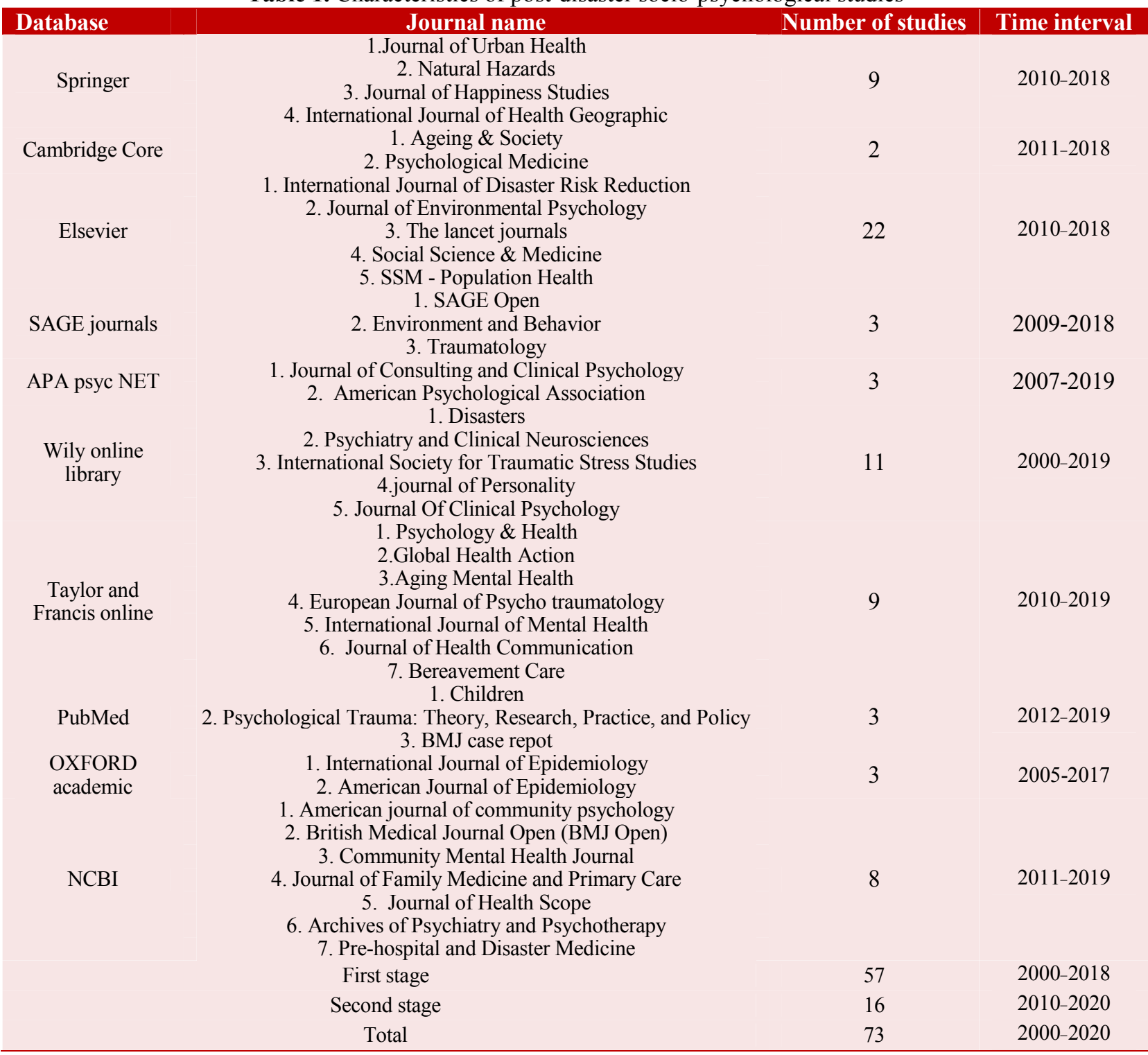




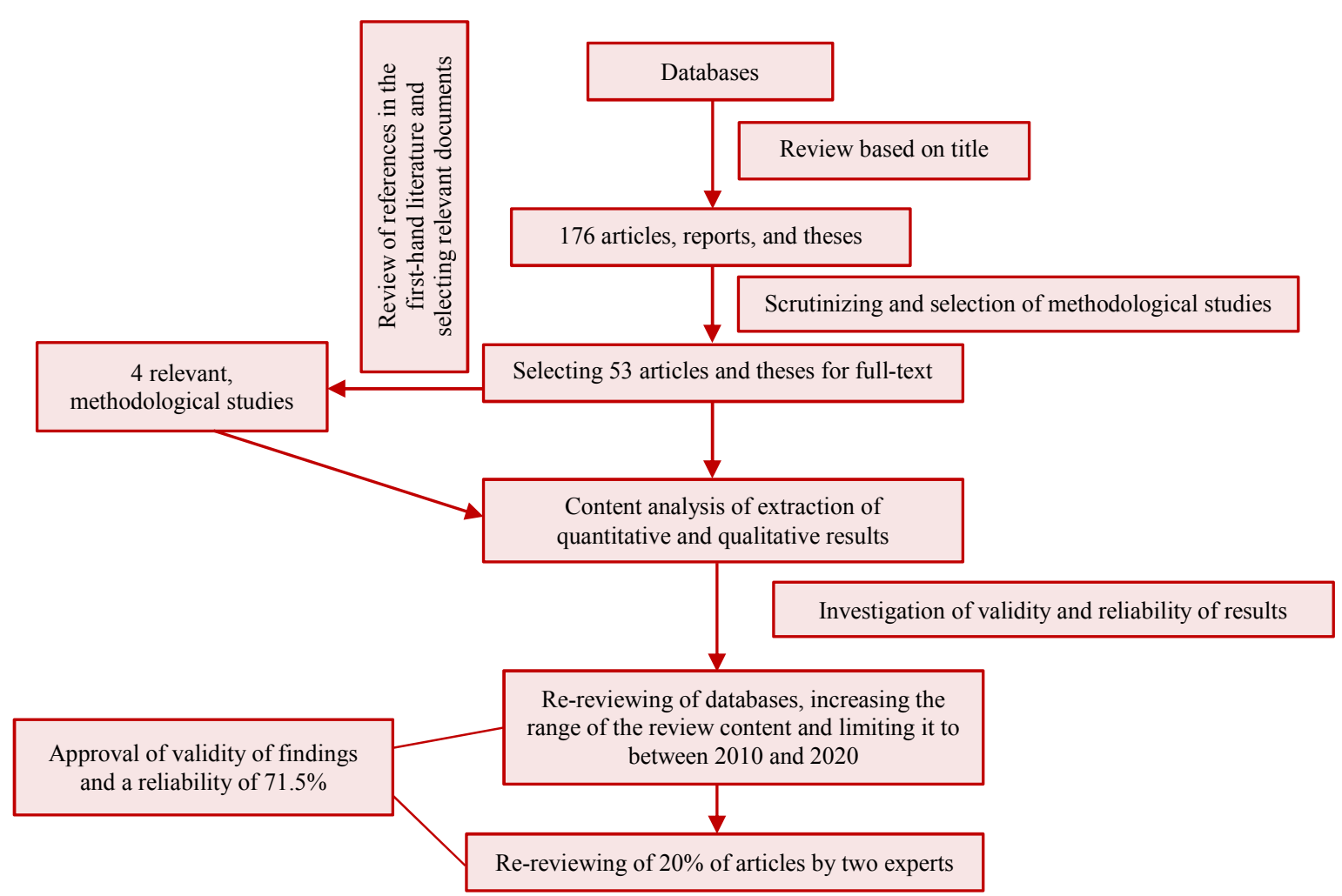

Figure 3. Research implementation process

The codes were extracted from the 57 selected articles in the initial stage of content analysis based on the components of research strategy, research project implementation, highlighted topics, sampling method, statistical population, and data collection tools, then these data were analyzed in Excel 2016 software and presented in the form of descriptive statistics using tables and figures.

In the second step, two techniques were employed to measure the reliability and consistency of the results. First, the review of the databases, increasing the content reviewed, and limiting the range of the studies to between 2010 and 2020 were performed to ensure the accuracy of the findings. At this stage, as feedback, the study keywords were re-examined in the databases and a content analysis was conducted on the new findings in this field, and then they were added to the study body. This limitation was intended to test the study findings. Second, a review of all selected studies was conducted by two independent researchers with the aim of extracting the reliability of the findings. In this section, a total of 73 extracted articles on which content analysis was performed were provided to two skilled researchers. $20 \%$ of these studies were selected using the random cluster sampling method and analyzed. According to the two experts, the study results were close to their findings as $68 \%$ and $75 \%$. The average of the values showed a reliability of the study findings up to $71.5 \%$ (Figure 3).

\section{Findings}

\section{Research plan}

The research plan was determined and organized according to the study subject, and this includes the quality and accuracy of the findings. In planning any research project, two issues are considered, the strategy selected for conducting the study and the implementation method.

Research implementation strategy: The studies reviewed had been implemented using various methodological strategies that will be described in detail.

Quantitative methods: This strategy had the highest frequency in the analysis with $49.12 \%$. Examining the reliability and consistency of the outputs in the second phase, it was found that in the last ten years, this value has changed to $49.29 \%$. In this category of studies, the studies with a correlation approach with $64.2 \%$, had the highest frequency compared to the experimental and quasi-experimental studies (Table 2). 
Qualitative methods: According to the analysis, between 2000 and 2018, 26.31\% of the studies was performed by qualitative method, while in the last decade, this rate has increased to $30.98 \%$. One of the reasons for this is the increase in focus and related studies in developing countries. In order to prove this point, in the second phase of the study, equally, 5 studies from developing countries and 5 studies from developed countries conducted between 2017 and 2020 were selected and compared. The findings, on the one hand, showed the increasing attention of developing countries to socio-psychological issues related to disasters, and on the other hand, showed the wide scope of application of qualitative research methods in countries such as Iran. Most of these studies have been performed using content analysis and grounded theory. In contrast, in developed countries, quantitative research is prominent and is generally performed using standard measurement tools and scales (Table 2).

Mixed method: Research experts in the field of consequences of a disaster, consider the mixed method research as one of the appropriate strategies including collection, analysis, and integration of quantitative and qualitative data to answer research questions (38). $15.78 \%$ of the studies in the field reviewed used the mixed quantitative and qualitative methods for research. The plan of combining quantitative and qualitative methods in these studies included: first; Parallel implementation of quantitative and qualitative studies and finally combining the findings, second; Parallel implementation of quantitative and qualitative studies, composition and analysis of findings and then reuse of quantitative tools to prove and increase the accuracy of the study findings, third; Collecting and analyzing data qualitatively and determining the effective indicators and components in the study, implementing quantitative method by determining the desired group and conducting research tests, and finally re-conducting qualitative research to analyze the data obtained from the quantitative study, and fourth; Collection and analysis of descriptive and multi-criteria data quantitatively and review of information qualitatively.

Evidence-based method: More than a decade ago, Friedman stated that although there is strong evidence for the effectiveness of cognitivebehavioral therapies for post-traumatic stress disorder, evidence-based research in disaster survivors is in its infancy. (39) Evidence-based method is potentially a practical alternative to experimental and quasi-experimental research projects and can be used in affected communities (40). This method involves the systematic evaluation of research evidence in therapeutic interventions to ensure the most effective and efficient treatment (23). Analysis of studies suggests that the rate of using this strategy in postdisaster socio-psychological investigations is lower than other strategies. Based on a study of related research backgrounds, research on American soldiers and veterans following the Iraq and Afghanistan wars can be pointed out (41-43). This method is based on therapeutic interventions, recording reports, and monitoring changes over time, and the common method is to analyze the data in the medical file. The variables examined include the choice of treatment type, rate of disease relief, and severity and changes of symptoms (44). Obstacles to exploiting this research strategy include the need for continuous monitoring of the subjects under study, access to medical records in great detail and adherence to ethical principles, limited research resources versus the need for time, and the high cost of this method. The rate of utilization of this method is very low between 2010 and 2020, confirming the findings of the first part of the content analysis.

Neuroscience-Based Method: In the field of neuroscience and disaster-related psychological problems, perhaps one of the earliest studies is the experiments accomplished by Maier and Seligman on shock in dogs, which led to the theory of learned helplessness, which is seen in both diseases of depression and PTSD (45). In 2013, Bathory studied the role of mind and cognition in collective trauma using brain hormones. According to him, in the experience of collective trauma, paying attention to the parts related to recall in the brain helps to heal the effects and the resulting psychosocial effects (46). In recent decade, the emergence of neurological catalysts has led to the in-depth study of the basic neurophysiological mechanisms that underlie complex human behaviors. In this regard, convincing evidence has been obtained regarding the involvement of the learned fear mechanism and its generalization, the response to stress, sleep disorder and nightmares, and emotional contexts in individuals with PTSD (47). In the first phase of the present content analysis, only one study was conducted by Massaro et al. using this 
strategy in 2018 after the 2009 L'Aquila earthquake in Italy using the electroencephalography (EEG) tool (48). In the second phase of content analysis, it was revealed that the scope of application of this method is increasing in international studies. In the last two years, between 2018 and 2020, four related studies have been added to the body of disaster literature. These studies examine the neural activity processes, social information (as opposed to non-social) process, and evaluation of the interaction of social information in processing with other stimulating characteristics, especially emotional meaning (49) and cognitive patterns of PTSD as well as focusing attention on threatening factors in the phenomenology of this disorder using the eye tracking tool (50).

Research project implementation: Disasters are a set of individual and collective stressful experiences with varying degrees of severity, accompanied by variable consequences over time. Thus, time and community factors are fundamental components in research planning (51). Furthermore, most of the disaster consequences emerge beyond a one-year period (18). Therefore, researchers have introduced two cross-sectional and longitudinal research projects that are most

Table 2. Quantitative and qualitative research approaches

\begin{tabular}{|c|c|c|}
\hline Strategy & Approach & Number \\
\hline \multirow[t]{2}{*}{ Quantitative } & $\begin{array}{l}\text { Experimental and quasi- } \\
\text { experimental studies }\end{array}$ & 10 \\
\hline & Correlational studies & 25 \\
\hline \multirow{4}{*}{ Qualitative } & Narrative research & 3 \\
\hline & Interpretation & 7 \\
\hline & Ethnography & 5 \\
\hline & Grounded theory & 6 \\
\hline \multicolumn{2}{|c|}{$\begin{array}{l}\text { Qualitative-quantitative (mixed } \\
\text { method) }\end{array}$} & 9 \\
\hline \multicolumn{2}{|c|}{ Neuroscience } & 5 \\
\hline \multicolumn{2}{|c|}{ Evidence-based } & 3 \\
\hline
\end{tabular}

Table 3. Duration of longitudinal studies/Time of start of cross-sectional studies/Sampling methods

\begin{tabular}{l|cc|}
$\begin{array}{l}\text { Research } \\
\text { plan }\end{array}$ & $\begin{array}{c}\text { Interval (longitudinal } \\
\text { study)/starting time } \\
\text { (cross-sectional study) }\end{array}$ & Number \\
\hline & 5 months to one year & 7 \\
Longitudinal & 2 to 2.5 years & 7 \\
study & 3 years & 5 \\
& 5 years & 4 \\
Cross- & 7 years & 1 \\
sectional & 15 years & 1 \\
\hline
\end{tabular}

widely used in post-traumatic studies $(52,53)$. Given the investigations, $61.4 \%$ of the studies used a cross-sectional research plan to advance the study (Table 3). Of these, 24 studies were conducted in developed countries, including the United States, Japan, the United Kingdom, Canada, and Australia, and 11 ones were conducted in developing countries such as Iran, Sri Lanka, and Indonesia. In longitudinal research, most studies have been conducted in developed countries and based on frequency, the United States, Japan, Canada, and Australia, respectively accounted for the highest numbers. Therefore, the research findings confirm the view of Norris and Elrod in which the lack of accurate information about pre-disaster conditions was one of the obstacles to longitudinal research in developing countries (54). Given the findings, longitudinal studies with a longer period of time (more than 5 years) have been less performed due to the limitations in the present research project. In the content analysis of post-incident studies in Iran, only one longitudinal study has been conducted, which was performed after the Bam earthquake in 2003 and in the time period of 15 days to 3 years after the event (55) (Table 3).

\begin{tabular}{|c|c|c|}
\hline \multirow[t]{7}{*}{ study } & \multirow{7}{*}{$\begin{array}{c}\text { disaster } \\
2 \text { years after the disaster } \\
3 \text { years after the disaster } \\
4 \text { years after the disaster } \\
5 \text { years after the disaster } \\
10 \text { years after the } \\
\text { disaster } \\
15 \text { years after the } \\
\text { disaster }\end{array}$} & \\
\hline & & 8 \\
\hline & & 5 \\
\hline & & 3 \\
\hline & & 11 \\
\hline & & 2 \\
\hline & & 1 \\
\hline \multicolumn{3}{|c|}{ Sampling method } \\
\hline Random & Cluster & Systematic \\
\hline 17 & 6 & 3 \\
\hline Voluntary & Snowball & Convenience \\
\hline 10 & 7 & 7 \\
\hline
\end{tabular}

\section{Target society}

Includes people who are the target of the studies related to human societies (56). In the event of a disaster, this definition includes individuals or groups who experience a traumatic event and are examined in relation to a specific subject (57). The criteria for this component have been examined in detail.

Sampling framework: In socio-psychological studies, it is challenging to select a sampling framework to achieve an appropriate statistical population representing the entire affected 
community. Determining the geographical area affected by the disaster is also very important (29). Selecting a large area or population results in the consideration of individuals who have not been or have been indirectly exposed to the disaster. As a result, these communities will affect the results (53). The next challenge is to find people willing to participate in the study in adverse and critical situations (58). Thus, the selection of the study population is one of the most effective and sensitive steps in the implementation of the study and requires consideration of several intervening factors that the researcher encounters in such areas. Sampling methods are listed in Table 3. According to the findings, one of the ways to facilitate these challenges is to use pre-disaster demographic information and to use the information of governmental and non-governmental organizations active in the affected areas.

Sample size: Given the objectives of each of the research implementation strategies, the study sample size lies in various ranges. Based on the analyses, the statistical population size was 81 to 9329 in quantitative studies, 4 to 125 in the qualitative studies, 201 to 1615 in mixed studies, 4 to 130 in evidence-based studies, and 15 to 40 in neuroscience studies (Figure 4).

Figure 4. Range of determination of statistical samples

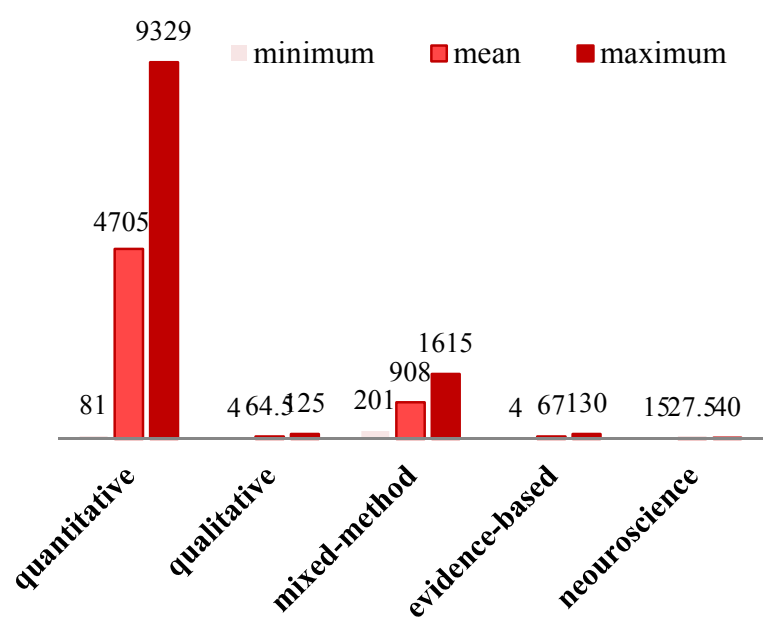

\section{Measurement of key structures}

In measuring key structures, two criteria of measurement tools and research topics were used in post-traumatic socio-psychological studies.

Data measuring and collection tools: Measuring and identifying the sociopsychological consequences and other related variables in post-disaster research is fraught with difficulties and ambiguities and requires appropriate data measurement and collection tools. On the other hand, one of the challenges in this field is the creation, regulation, and validation of all quantitative instruments of evaluation and measurement in the United States and developed countries (59) and the lack of their correlation and cultural validity in other areas affected by disasters. Given the comprehensive study and analysis of studies around the world, the frequency of use of the measurement instruments can be considered as one of the criteria for their efficiency in other countries. In qualitative research, telephone, deep, and semi-structured interview tools, as well as participatory and field observations have the highest frequency in data collection. In quantitative research, the structured and standardized questionnaires have the highest frequency, indicating the efforts of researchers in adapting tools to the context of research.

After that, the frequency and range of application of the standard PTSD questionnaire (PCL) and the psychological anxiety assessment questionnaire in post-traumatic psychosocial studies are significant. It is concluded that the performance and capabilities of these two tools in the affected areas are slightly higher than other standard assessment and measurement tools (Figures 5 and 6). 


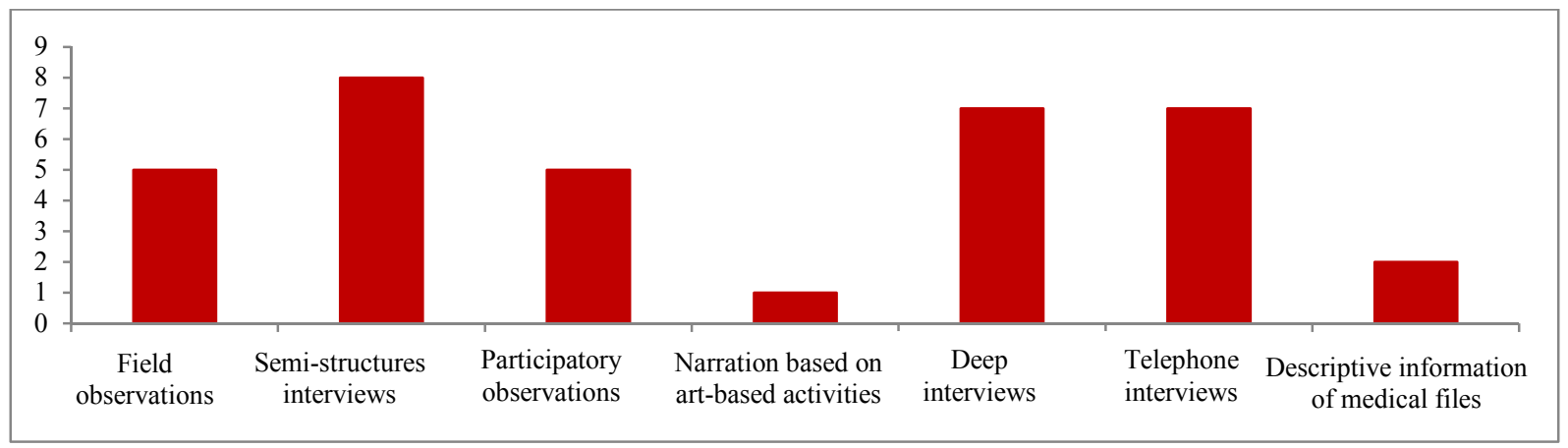

Figure 5. Data collection tools in qualitative studies

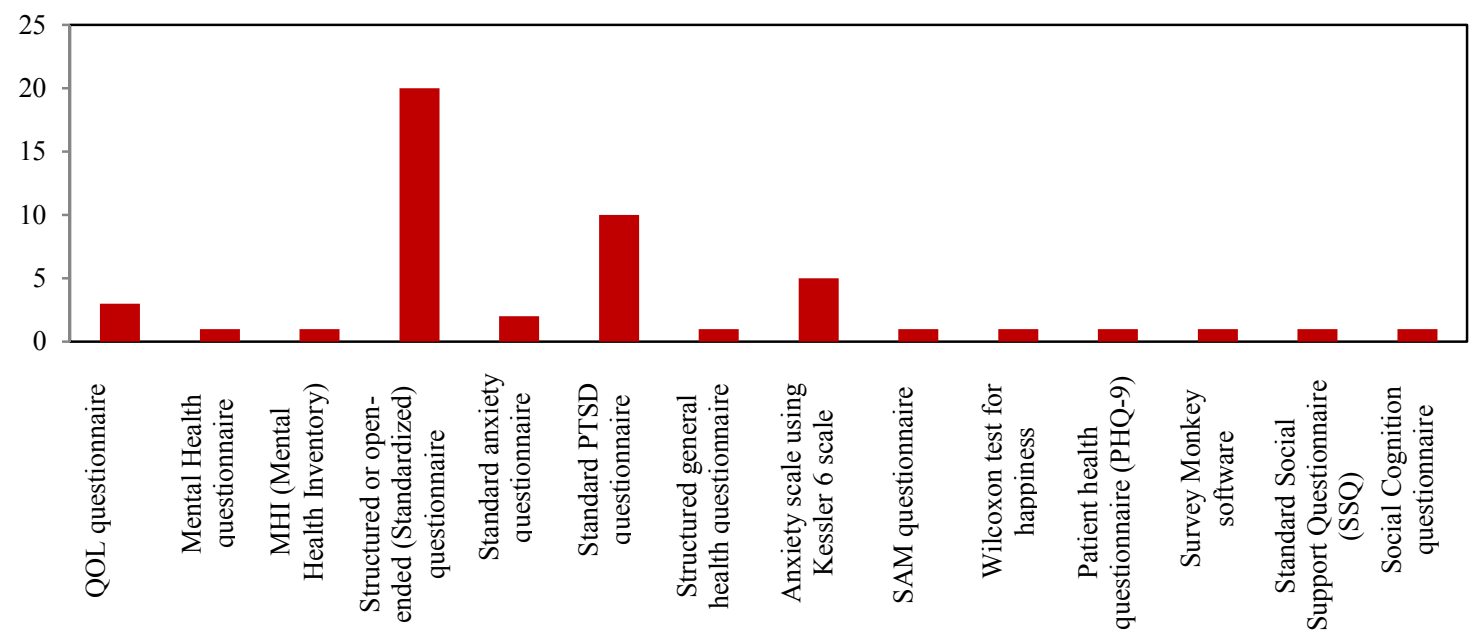

Figure 6. Data collection tools in quantitative studies

Study subjects: Based on the findings, the most important subjects associated with the consequences of the disaster were PTSD, anxiety, and depression, and in post-disaster social-psychological rehabilitation interventions, welfare and mental health, perception of social support, and mental resilience accounted for the highest frequency (Figure 7).

By dividing the components into two individual and collective scales (Figure 8), it was found that after the disaster, on in the individual scale, PTSD, depression, and anxiety in psychological consequences and quality of life (QOL) and psychological resilience in individual mental health, respectively had the highest frequency and concentration. On the collective scale, indicators of collective mental health, including perceptions of social support, well-being, and collective mental health, environmental satisfaction, and indicators of collective living and efficiency, were the main subjects of study, respectively.

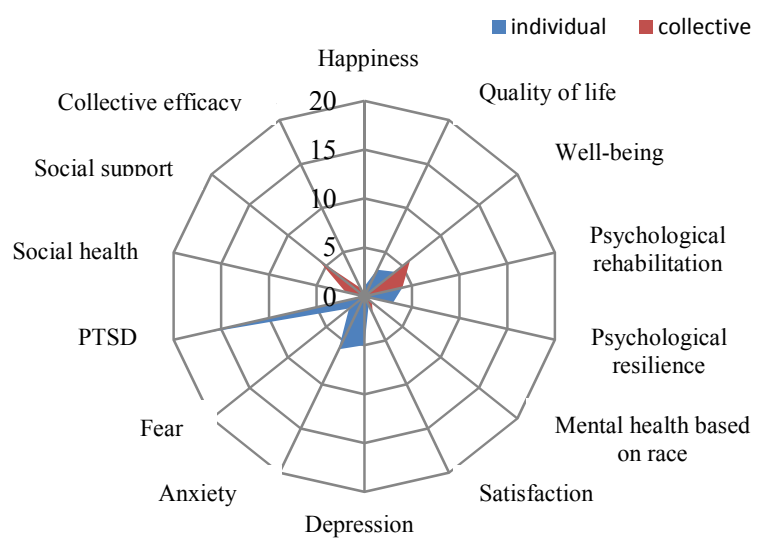

Figure 8. Emphasis on individual and collective scales 


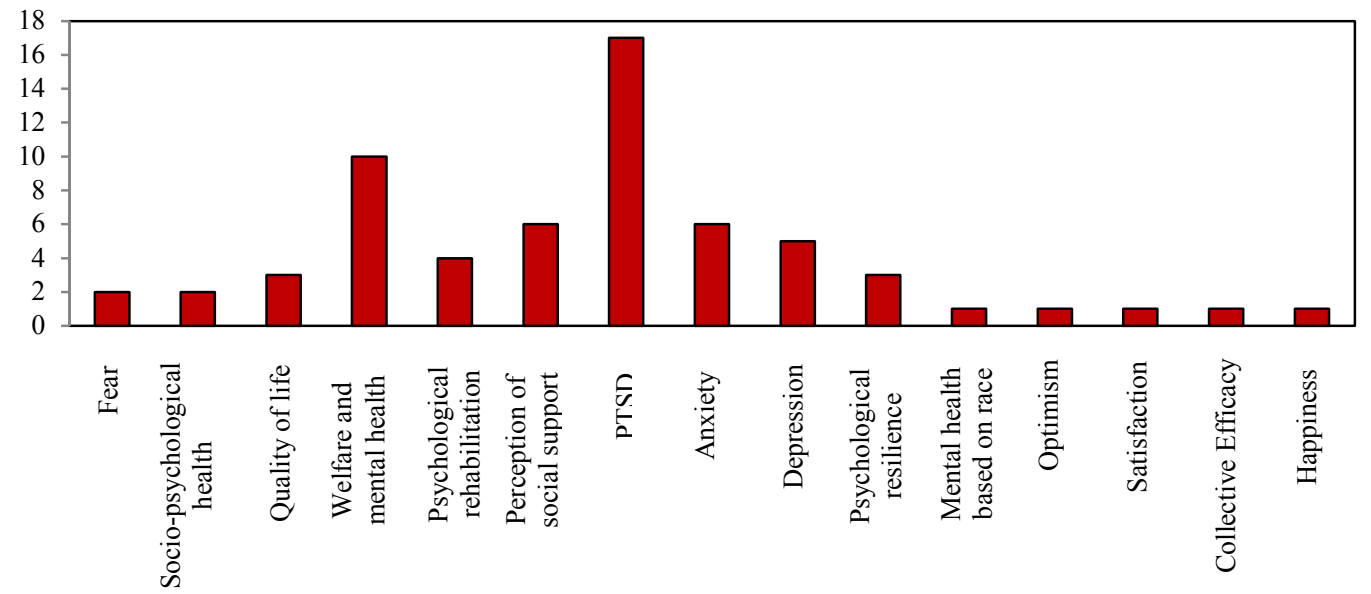

Figure 7. Study subjects in post-disaster social-psychological studies

\section{Discussion and Conclusion}

According to the findings, the study of the consequences of the disaster differs in many ways from other areas. The main reason is the focus on the occurrence or outcome of some discrete events in the post-disaster environment. The findings of the present analysis indicated the increasing trend of disasters and the subsequent various socio-psychological consequences, along with the growth of studies in this field, because most of the studies were conducted between 2016 and 2020 .

In the first place, the design of any study is one of the most important issues. As the researchers emphasize, the research design is more important than the method of analyzing the results (60), so the scientific integrity of the study and the validity of the findings depend significantly on the research design (61). Regarding the research strategies, it was revealed that quantitative research accounts for the largest percentage and focus of the global research, and according to the literature, quantitative research in PTSD studies is a traditional methodological strategy for data collection (62), which is used for measurement and control (63). Among the reasons for this issue can be considered the standard and available measuring instruments in this field. In the second place, the findings indicated the application of qualitative research. Qualitative research is commonly used to identify, describe, and explain phenomena. Psychotherapists of post-disaster sociopsychological complications often collect and analyze qualitative data through narratives, listening skills, and observation of common trends and patterns $(64,65)$. Qualitative methods are used to achieve several goals in the context of examining the socio-psychological effects of a disaster firstly to obtain a rich understanding of specific phenomena (66) and secondly, understand the impact of disasters on the behavior of individuals, groups, and organizations (67). In the third place is the frequency of mixed studies (68). According to Teddlie and Tashakkori, when mixed research projects are used together, quantitative and qualitative research traditions that have great potential to complement each other provide a more comprehensive level of insight and understanding by combining width and depth, exploration, and approval (69). Given the reasoning based on these analyses, this strategy has advantages over quantitative or qualitative research. Spending less time and money, increasing the accuracy of findings due to the attention to the subject from double views, and thus achieving valid outputs are among these advantages. Additionally, in the application of neuroscience-based methods, the expanding trend of this strategy in the field of postdisaster socio-psychological consequences shows the focus of future research horizons on this method, due to the high potential of application in individual and collective post-traumatic research and creating a deep insight into socio-psychological mechanisms of the effect of interventions such as environmental stimuli and social support. An important issue in this regard is the implementation of this strategy with the parallel application of questionnaires and standard measurement scales, which in a way makes the application of research methods related to neuroscience due to appropriate tools of quantitative measurements. 
On the other hand, an important issue in posttraumatic psychosocial research is the concept of time. In this regard, it was found that crosssectional studies are faced with a time ambiguity in the relationship between exposure to a disaster and its consequences. It is difficult to determine whether exposure to a disaster has caused socio-psychological consequences or problems. In these studies, it was not possible to form any relationship between predictors and outcomes in relation to time (29). In contrast, prospective or longitudinal studies have fewer of these limitations and are useful for studying long-term socio-psychological pathways (58). In studies, many researchers have emphasized the importance of futuristic designs and longitudinal analysis strategy (70). In their study, King and King confirmed the causal inference validity in traumatic studies with a life-long perspective and used the available longitudinal methods to better understand the course of post-traumatic psychological consequences (71). Friedman also emphasized that in research related to the consequences of a disaster, a longitudinal research plan is clearly needed to accurately assess the effects (39). However, what is clear is that longitudinal research in developing countries is very rare, and one of the reasons for its limitation is the lack of information about the sociopsychological conditions of pre-disaster communities, time constraints, resource constraints, and the decline of the study community over time. The results suggest that despite the many challenges in such studies, the frequency of the criteria analyzed is astonishingly limited to specific cases. Given the findings, the most common methodological findings of research in post-disaster psychosocial studies were cross-sectional research with quantitative strategy, random sampling, standardized structured questionnaire tools for data collection, and large statistical population.

Besides, on the research subject, on the individual scale, the focus was on individual psychological consequences, such as PTSD, anxiety, and depression. In contrast, the number of studies based on individual health indicators and psychological rehabilitation was less. This problem manifests itself in another way on a collective scale. In this scale, the consequences of collective trauma and its characteristics have been less considered than the indicators related to collective mental health and recovery such as collective well-being and mental health, QOL, collective efficiency, social support, and environmental satisfaction. On the individual scale, in addition to assessing and assessing the psychological consequences of a disaster, it is necessary to address issues related to the recovery and mental health of the individual and on a collective scale to more deep understanding of the socio-psychological consequences of the disaster.

At the same time, as the findings, studies have been evolving significantly in terms of theoretical and methodological approaches over the past decade. While research in this field relies heavily on traditional methods, advances in computer modeling and measurement tools provide new solutions to the ambiguous socio-psychological issues of the disaster and provide opportunities for the development of knowledge on the indefinite subjects. On the horizon ahead of the post-disaster socio-psychological research, it seems that in addition to quantitative research as the dominant method in this field, researchers have focused on neuroscience on individual-collective scales. The innovations, along with the use of other common methodological approaches, seem to allow for achieving hidden variables in research. This requires standardization, validation, and reliability of standardized measurement scales in different cultures and regions affected by the disaster.

\section{Acknowledgments}

The present article was extracted from a $\mathrm{PhD}$ thesis on architecture entitled "Housing Reconstruction Based on Post-Earthquake SocioPsychological Resilience", which was approved by Shahid Rajaee Teacher Training University, Tehran, Iran. The authors would like to appreciate all those who helped to accomplish this study.

\section{Conflict of Interests}

Authors have no conflict of interests.

\section{References}

1. Sundnes KO, Birnbaum ML. Health disaster management guidelines for evaluation and research in the utstein style. Prehospital and Disaster Medicine 2003; 17(3).

2. Goldman E, Galea S. Mental health consequences of disasters. Annu Rev Public Health 2014; 35: 169-83.

3. United Nations Office for Disaster Risk Reduction (UNDRR). Sendai framework for disaster risk reduction 2015-2030 [Online]. [cited 2015]; Available from: URL: 
https://www.undrr.org/publication/sendai-frameworkdisaster-risk-reduction-2015-2030

4. Bolin R. Disasters and long-term recovery policy: A focus on housing and families. Review of Policy Research 1985; 4(4): 709-15.

5. Leitmann J. Cities and calamities: Learning from postdisaster response in Indonesia. J Urban Health 2007; 84(3 Suppl): i144-i153.

6. Tran TA. Developing disaster resilient housing in Vietnam: Challenges and solutions. Berlin, Germany: Springer; 2015.

7. Peacock WG, Dash N, Zhang Y, Van Zandt S. Postdisaster sheltering, temporary housing, and permanent housing recovery. In: Rodriguez H, Donner W, Trainor JE, Editors. Handbook of disaster research. Berlin, Germany: Springer; 2017.

8. Johnson C, Lizarralde G. Post-disaster housing and reconstruction. In: Smith SJ, Editor. International encyclopedia of housing and home. Philadelphia, PA: Elsevier; 2012. p. 340-6.

9. Duyne Barenstein JE. Towards sustainable post-disaster housing and building technologies: Issues and challenges with special reference to India. In: Bolay JC, Schmid A, Tejada G, Hazboun E, Editors. Technologies and Innovations for Development: Scientific Cooperation for a Sustainable Future. Berlin, Germany: Springer Science \& Business Media; 2012.

10. Wardak ZS, Coffey V, Trigunarsyah B. Critical factors for successful housing reconstruction projects following a major disaster. Proceedings of the $19^{\text {th }}$ Triennial CIB World Building Congress; 2013 May 5-9; Brisbane, Queensland.

11. Aquilino MJ. Beyond Shelter: Architecture for crisis. London, UK: Thames \& Hudson; 2011.

12. Gerhart J, Daphna C, Hobfoll ES. Traumatic stress in overview: Definition, context, scope, and long-term outcomes. In: Cherry KE, Editor. Traumatic stress and long-term recovery: Coping with disasters and other negative life events. Berlin, Germany: Springer; 2015.

13. Donner W, Diaz W. Methodological issues in disaster research. In: Rodriguez $\mathrm{H}$, Donner $\mathrm{W}$, Trainor JE, Editors. Handbook of disaster research. Berlin, Germany: Springer; 2017.

14. Bolin R, Stanford L. The Northridge earthquake: Community? Based Approaches to Unmet Recovery Needs. Disasters 1998; 22(1): 21-38.

15. Lindell MK, Prater CS. Assessing Community Impacts of Natural Disasters. ASCE; 2003.

16. Paton D. Disaster resilient communities: Developing and testing an all-hazards theory. IDRiM Journal 2013; 3(1): $1-17$.

17. Edgeley CM, Paveglio TB. Community recovery and assistance following large wildfires: The case of the Carlton Complex Fire. Int J Disaster Risk Reduct 2017; 25: 137-46.

18. Norris FH, Friedman MJ, Watson PJ, Byrne CM, Diaz E, Kaniasty K. 60,000 disaster victims speak: Part I. An empirical review of the empirical literature, 1981-2001. Psychiatry 2002; 65(3): 207-39.

19. Mezinska S, Kakuk P, Mijaljica G, Waligora M, O'Mathuna DP. Research in disaster settings: A systematic qualitative review of ethical guidelines. BMC Med Ethics 2016; 17(1): 62.

20. Drabek TE. Methodology of studying disasters: Past patterns and future possibilities. American Behavioral Scientist 1970; 13(3): 331-43.

21. Mileti D. Sociological method and disaster research. In: Dynes RR, De Marchi B, Pelanda C, Editors. Sociology of disasters: Contribution of sociology to disaster research. Milan, Italy: Franco Angeli; 1987.

22. Stallings RA. Methods of disaster research. Bloomington, Indiana: Xlibris Corporation; 2003.

23. Iribarren J, Prolo P, Neagos N, Chiappelli F. Posttraumatic stress disorder: Evidence-based research for the third millennium. Evid Based Complement Alternat Med 2005; 2(4): 503-12.

24. Indah R. Probing problems: Dilemmas of conducting an ethnographic study in a disaster-affected area. Int $\mathrm{J}$ Disaster Risk Reduct 2018; 31: 799-805.

25. Mcfarlane A, Norris H. Definitions and concepts in disaster research. In: Norris FH, Editor. Methods for disaster mental health research. New York, NY: Guilford Press; 2006.

26. Yasman I, Davis J. Architecture and reconstruction planning. Trans. Fallahi A. Tehran, Iran: Shahid Beheshti University Press; 2006.

27. Bureau for Crisis Prevention and Recovery. Disaster risk assessment [Online]. [cited 2010]; Available from: URL: https://www.undp.org/content/dam/undp/library/crisis $\% 2$ 0prevention/disaster/2Disaster\%20Risk\%20Reduction $\% 2$ 0-\%20Risk\%20Assessment.pdf

28. Fritz CE, Danzig ER, Killian LM, Raker JW, Clifford RA, Perry SE, et al. An introduction to methodological problems of field studies in disasters: A special report. Washington, DC: National Academy of Sciences, National Research Council; 1956.

29. Galea S, Nandi A, Vlahov D. The epidemiology of posttraumatic stress disorder after disasters. Epidemiol Rev 2005; 27(1): 78-91.

30. Kulka RA, Schlenger WE. Survey research and field designs for the study of posttraumatic stress disorder. In: Wilson JP, Raphael B, Editors. International handbook of traumatic stress syndromes. Berlin, Germany: Springer; 1993. p. 145-55.

31. Amaratunga $\mathrm{N}$, Haigh $\mathrm{R}$, Ingirige $\mathrm{B}$. Post-disaster housing reconstruction in Sri Lanka: What methodology? SAGE Open 2015; 5(3): 1-7.

32. Holsti OR. Content Analysis. In: Lindzey G, Aronson E, Editors. The handbook of social psychology. Boston, MA: Addison-Wesley Publishing Company; 1968.

33. Sandelowski M. Theory unmasked: the uses and guises of theory in qualitative research. Res Nurs Health 1993; 16(3): 213-8.

34. Roudini J, Khankeh HR, Witruk E. Disaster mental health preparedness in the community: A systematic review study. Health Psychol Open 2017; 4(1): 2055102917711307.

35. Momeni Rad A, Aliabadi K, Fardanesh H, Mazini N. Qualitative content analysis in research tradition: Nature, stages and validity of the results. Educational Measurement 2013; 14(4): 187-222. [In Persian].

36. Iman M, Noshadi M. Qualitative content analysis. Pazhuhesh, 2012; 3(2): 15-44. [In Persian]. 
37. Coe K, Scacco JM. Quantitative content analysis. In: Davis CD, Potter RF, Editors. The international encyclopedia of communication research Methods. Hoboken, NJ: Wiley; 2017.

38. Creswell JW, Plano Clark VL. Designing \& conducting mixed methods research. Thousand Oaks, CA: SAGE Publications; 2007.

39. Friedman M.J. Disaster mental health research challenges for the future. In: Norris FH, Galea S, Matthew F, Patricia W, Editors. Methods for disaster mental health research. New York, NY: Guilford Press; 2006.

40. Gibson Le, Hamblen J, Zvolensky M, Vujanovic AA. Evidence-based treatments for traumatic stress. In: Norris FH, Galea S, Matthew F, Patricia W, Editors. Methods for disaster mental health research. New York, NY: Guilford Press; 2006.

41. Hartman Jesse GN. Therapeutic spaces for veterans with PTSD [MSc Thesis]; Columbus, OH: The Ohio State University; 2012

42. Greer V. Designing for invisible injuries: An exploration of healing environments for posttraumatic stress [MSc Thesis]; Louis, MO: Washington University in St. Louis; 2018.

43. Khanade K, Rodriguez-Paras C, Sasangohar F, Lawley S. Investigating architectural and space design considerations for Post-Traumatic Stress Disorder (PTSD) patients. Proceedings of the $62^{\text {nd }}$ Human Factors and Ergonomics Society Annual Meeting; 2018 Oct. 1-5; Philadelphia, PA

44. Doran JM, DeViva J. A naturalistic evaluation of evidence-based treatment for veterans with PTSD. Traumatology 2018; 24(3): 157-67.

45. Maier SF, Seligman ME. Learned helplessness: Theory and evidence. J Exp Psychol 1976; 105(1): 3-46.

46. Bathory DS, Lajbensperger $N$. The collective mind in design and relational dynamics. Zbornik Matice Srpske za Likovne Umetnosti 2014; (42): 215.

47. Liberzon I, Ressler K. Neurobiology of PTSD: From Brain to Mind. Oxford, UK: Oxford University Press; 2016.

48. Massaro G, Altavilla D, Aceto P, Pellicano GR, Lucarelli G, Luciani $M$, et al. Neurophysiological Correlates of Collective Trauma Recall in 2009 L'Aquila Earthquake Survivors. J Trauma Stress 2018; 31(5): 687-97.

49. Schacht A, Vrticka P. Spatiotemporal pattern of appraising social and emotional relevance: Evidence from event-related brain potentials. Cognitive, Affective, \& Behavioral Neuroscience 2018; 18: 1172-87.

50. Lazarov A, Suarez-Jimenez B, Tamman A, Falzon L, Zhu X, Edmondson DE, et al. Attention to threat in posttraumatic stress disorder as indexed by eye-tracking indices: A systematic review. Psychol Med 2019; 49(5): 705-26.

51. Norris FH. Disaster research methods: past progress and future directions. J Trauma Stress 2006; 19(2): 173-84.

52. Norris FH, Friedman MJ, Watson PJ. 60,000 disaster victims speak: Part II. Summary and implications of the disaster mental health research. Psychiatry 2002; 65(3): 240-60.

53. Galea S, Maxwell AR. Methodological challenges in studying the mental health consequences of disasters. Mental health and disasters 2009; 34: 579-93.
54. Norris FH, Elrod CL. Psychosocial consequences of disaster a review of past research. In: Norris FH, Galea S, Matthew F, Patricia W, Editors. Methods for Disaster Mental Health Research. New York, NY: Guilford Press; 2006.

55. Khankeh HR, Khorasani-Zavareh D, Johansson E, Mohammadi R, Ahmadi F, Mohammadi R. Disaster health-related challenges and requirements: A grounded theory study in Iran. Prehosp Disaster Med 2011; 26(3): 151-8.

56. Wikipedia the Free Encyclopedia. Research participant [Online]. [cited 2019]; Available from: URL: https://en.wikipedia.org/wiki/Research_participant

57. Fleischman AR, Collogan L, Farris T. Ethical issues in disaster research. In: Norris FH, Galea S, Matthew F, Patricia W, Editors. Methods for disaster mental health research. New York, NY: Guilford Press; 2006.

58. Galea $S$, Tracy M. Participation rates in epidemiologic studies. Ann Epidemiol 2007; 17(9): 643-53.

59. Neria Y, Nandi A, Galea S. Post-traumatic stress disorder following disasters: A systematic review. Psychol Med 2008; 38(4): 467-80.

60. Campbell MJ, Machin D. Medical Statistics: A Commonsense Approach. Hoboken, NJ: Wiley; 1999.

61. Parab S, Bhalerao S. Study designs. Int J Ayurveda Res 2010; 1(2): 128-31.

62. Ruggiero KJ, Rheingold AA, Resnick HS, Kilpatrick DG, Galea S. Comparison of two widely used PTSDscreening instruments: Implications for public mental health planning. J Trauma Stress 2006; 19(5): 699-707.

63. Miller WL, Crabtree BF. Clinical research: A multi method typology and qualitative read map. In: Crabtree BF, Miller WL, Editors. Doing qualitative research. Thousand Oaks, CA: SAGE Publications; 1999. p. 3-30.

64. Siegel DJ, van der Kolk B. Trauma and the body: A Sensorimotor approach to psychotherapy (Norton Series on Interpersonal Neurobiology). New York, NY: W. W. Norton \& Company; 2006.

65. Scaer RC. The trauma spectrum: Hidden wounds and human resiliency. New York, NY: Norton; 2005.

66. Geertz C. The interpretation of cultures. New York, NY: Basic Books; 1973.

67. Oliver-Smith A. Anthropological research on hazards and disasters. Annu Rev Anthropol 1996; 25: 303-28.

68. Palinkas LA. Qualitative approaches to studying the effects of disasters. In: Norris FH, Galea S, Matthew F, Patricia W, Editors. Methods for disaster mental health research. New York, NY: Guilford Press; 2006.

69. Teddlie C, Tashakkori A. Major issues and controversies in the use of mixed methods in the social and behavioral sciences. In: Tashakkori A, Teddlie C, Teddlie CB, Editors. Handbook of mixed methods in social \& behavioral research. Thousand Oaks, CA: SAGE; 2003. p. 3-50.

70. Grace M, Green B, Lindy J. multiple diagnosis in posttraumatic stress disorder. J Nerv Ment Dis 1989; 177: 329-325.

71. King DW, King LA. Validity issues in research on Vietnam veteran adjustment. Psychol Bull 1991; 109(1): $107-24$. 